\title{
Cำuestáo
}

\section{Modelo de maturidade em gestão do conhecimento: uma visão diacrônica}

\author{
Anderson Luís Cambraia Itaborahy \\ Doutorando; Universidade de Brasília, Brasília, DF, Brasil; \\ anderson.itaborahy@gmail.com \\ Renato Plácido Mathias Machado \\ Mestre; Universidade Católica de Brasília, Brasília, DF, Brasil; \\ renatomachadodf@hotmail.com \\ Lillian Maria Araújo de Resende Alvares \\ Doutora; Universidade de Brasília, Brasília, DF, Brasil; \\ lillianalvares@unb.br
}

\begin{abstract}
Resumo: O presente artigo propõe um modelo de maturidade em gestão do conhecimento, a partir de levantamento na literatura dos modelos existentes, observados os fundamentos e a evolução da gestão do conhecimento. O método utilizado foi a pesquisa exploratória qualitativa, com revisão de literatura científica baseado no ranking criado pelo aplicativo de acesso livre Publish or Perish, utilizando uma variedade de fontes de dados científicas (incluindo Google Scholar e Microsoft Academic Search). O modelo resultante atende plenamente à ISO 30401 (Sistemas de Gestão do Conhecimento), com seis dimensões: Pessoas, Cultura, Governança, Processos, Arquitetura Organizacional e Infraestrutura e Tecnologia, representando os principais habilitadores do conhecimento e seis níveis de maturidade: 0 - Indivíduo, 1 Grupo, 2 - Organização, 3 - Inovação, 4 - Rede, 5 - Plenitude, representando o caminho de evolução da gestão do conhecimento. $\mathrm{O}$ modelo proposto se baseia no conceito de conhecimento como um fenômeno social e mental que não pode ser gerenciado diretamente. Conclui-se, então, que a maturidade da gestão do conhecimento numa organização pode ser representada como níveis de maturidade individuais para um conjunto de habilitadores do conhecimento, indicando o perfil do sistema de gestão do conhecimento e mostrando quão efetivo pode ser.
\end{abstract}

Palavras-chave: Modelo de maturidade. Gestão do conhecimento. Modelo de maturidade em gestão do conhecimento. ISO 30401.

\section{Introdução}

Modelos de maturidade se constituem em uma série de níveis sequenciais que apontam um caminho de evolução prescrito para determinado conjunto de 
elementos de uma organização, levando-os de um estágio inicial a outros de maior maturidade. No qual maturidade representa o grau de capacidade da organização para realizar o que se propõe, dominando os elementos e gerenciando-os de forma efetiva. Aplicar um modelo de maturidade a um determinado espaço - uma organização, por exemplo - e propor caminhos de evolução, parte da premissa de que existem padrões previsíveis ou desejáveis de evolução que podem ser sistematizados.

Este estudo pretende demonstrar que a abordagem da gestão do conhecimento por modelo de maturidade pode ser uma estratégia para implantação deste processo organizacional. O objetivo do estudo é apresentar um modelo de maturidade em gestão do conhecimento.

Busca-se oferecer diretrizes que permitam a uma organização, seja ela uma empresa, um órgão governamental ou do terceiro setor, compreender sua capacidade corrente de gestão do conhecimento e planejar sua evolução. Desta forma, é apresentada uma contribuição que vem somar às abordagens emergentes apontadas por Kraemer et al. (2017).

O termo diacrônico remete às mudanças de um fenômeno ao longo do tempo, tendo sua origem na obra do linguista Ferdinand de Saussure (18571913). No contexto deste estudo, diacrônico refere-se à compreensão da evolução do amadurecimento organizacional e, em particular, ao desenvolvimento da maturidade em gestão do conhecimento no período compreendido entre o início da década de 1990 e o fim da década de 2010. Os marcos referem-se à proposição do Capability Maturity Model for Software (PAULK et al., 1993), desenvolvido com foco nos processos de Engenharia de Software, mas que é a base de grande parte das propostas de modelos de maturidade em todas as áreas do conhecimento, e finaliza a jornada com a ISO 30401 - Knowledge Management Systems, de 2018.

No restante deste texto, após a descrição da metodologia (seção 2), serão apresentados brevemente fundamentos de modelos de maturidade (seção 3), conceitos e modelos da gestão do conhecimento (seção 4) e modelos propostos para maturidade da gestão do conhecimento (seção 5). Esses conceitos serão consolidados no modelo proposto (seção 6). Nas considerações finais é 
apresentada a consolidação dos resultados alcançados e apontadas perspectivas de trabalhos futuros.

\section{Metodologia}

A metodologia adotada foi a pesquisa exploratória qualitativa, baseada em revisão de literatura científica. A fonte da revisão foi o ranking criado pelo aplicativo de acesso livre Publish or Perish, que recupera e analisa citações acadêmicas, utilizando uma variedade de fontes de dados científicas (incluindo Google Scholar e Microsoft Academic Search). As citações brutas obtidas são analisadas, apresentando-se as seguintes métricas: número total de artigos e número total de citações, média de citações por artigo, citações por autor, artigos por autor e citações por ano, contemporaneidade, a taxa de citação ponderada pela idade, a análise do número de autores por artigo, dentre outras.

Os termos de busca foram "modelos de maturidade", "modelos de maturidade em gestão do conhecimento" e suas versões em inglês. Os artigos relacionados foram selecionados, numa primeira etapa, a partir da leitura dos resumos e, numa etapa posterior, pela leitura e análise integral dos textos. A essa relação, foram incluídos os textos mais frequentemente citados, formando a base de referência do estudo para a elaboração do modelo de maturidade em gestão do conhecimento.

\section{Modelos de maturidade}

Os modelos de maturidade ganharam projeção a partir do sucesso do Capability Maturity Model for Software - SW-CMM (PAULK et al., 1993) ${ }^{1}$, desenvolvido com foco nos processos de Engenharia de Software. O modelo apontava uma estrutura em cinco níveis de maturidade para uma organização onde cada nível contemplava um conjunto de áreas-chave que deveriam receber o esforço de evolução. Nesse caminho, o Capability Maturity Model Integration - CMMI (2001) ampliou o escopo de processos e organizações, oferecendo uma alternativa mais genérica onde os níveis de maturidade ou capacidade seriam avaliados para cada um de um conjunto de vários processos. 
O Projeto SPICE (DROUIN, 1999)² trilhou caminho semelhante, enfatizando em sua estrutura a avaliação não da organização como um todo, mas de cada processo individualmente, permitindo a adaptação a diferentes contextos. Essa estrutura tornou-se um padrão de fato, tendo sido usada também pelo COBIT 2019 (ISACA, 2019) para avaliar a capacidade e maturidade na governança da informação e da tecnologia nas organizações.

Lasrado, Vatrapu e Andersen (2015) estudaram os principais modelos de maturidade e identificaram seus elementos principais, conforme ilustrados na Figura 1, onde as dimensões correspondem à decomposição do espaço que está sendo observado como, por exemplo, um conjunto de processos ou elementos em uma organização, e os níveis ao grau de maturidade do elemento avaliado.

Figura 1 - Estrutura básica de um modelo de maturidade.

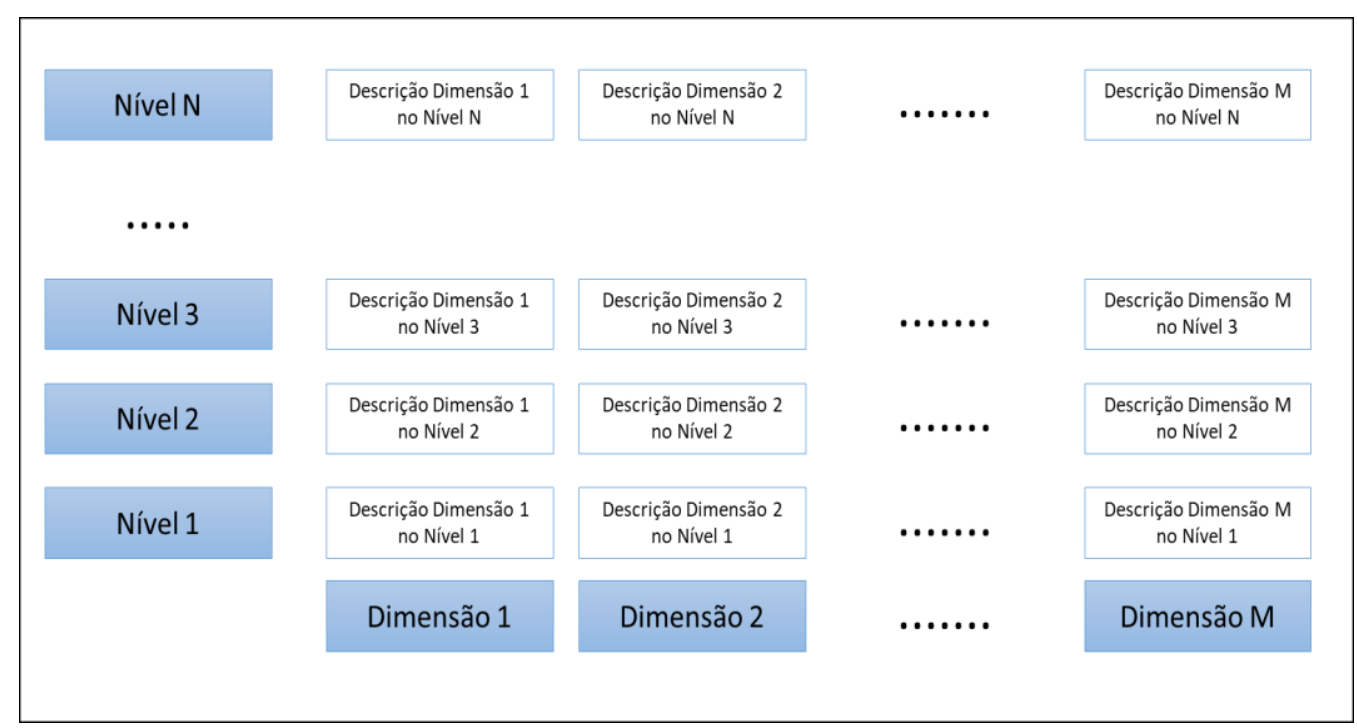

Fonte: Adaptado de Lasrado, Vatrapu e Andersen (2015).

Essa estrutura permite planejar a estratégia de evolução do conjunto de dimensões que melhor atenda aos objetivos e ao contexto da organização. Desta forma, evita-se uma estrutura rígida, linear e invariável de evolução, como as que Escrivão e Silva (2019) apontam como limitação em vários dos modelos existentes. Permite ainda comparar dimensões específicas entre áreas distintas de uma mesma organização ou entre diferentes organizações que se utilizem do mesmo modelo. 


\section{Gestão do conhecimento}

A ideia de gestão do conhecimento como uma disciplina ganhou popularidade ao final da década de 1990 (DALKIR, 2017). A preocupação em registrar e transmitir conhecimentos, entretanto, não é algo novo, mas ganhou nova dimensão com a evolução tecnológica que trouxe a possibilidade de acesso e compartilhamento de grandes volumes de informação.

Com a informação abundante e de acesso relativamente fácil, o diferencial competitivo já não está ali e sim no conhecimento que não pode ser codificado ou facilmente distribuído, mas que é capaz de extrair o valor potencial da informação disponível - selecionando, interpretando e aplicando na tomada de decisão (PRUSAK, 2001).

\subsection{Conceito de conhecimento}

Dalkir (2017) pesquisou conceitos de gestão do conhecimento, identificando 72 que considerou razoáveis. Essa multiplicidade decorre da importância do conhecimento em diversas áreas e, também, da própria natureza multidisciplinar da gestão do conhecimento, que torna difícil definir claramente seus limites.

Da mesma forma, conhecimento é também um termo polissêmico e de difícil definição. Ainda que não seja o objetivo desta discussão construir tal definição, faz-se necessário estabelecer os conceitos de conhecimento e de gestão do conhecimento que balizarão este trabalho.

Farradane (1980) vê o conhecimento como uma estrutura mental do indivíduo da qual este pode extrair parte e enviá-la codificada como uma mensagem - direta ou indireta - a outro indivíduo. O resultado dessa codificação é uma informação que seria uma representação de parte do conhecimento, traduzida em linguagem. O indivíduo receptor irá absorver essa informação e interpretá-la com base em seu conhecimento previamente existente e, eventualmente, incorporá-la a sua própria estrutura cognitiva, que assim será modificada.

Brookes (1980) representa informação e conhecimento, a partir de uma equação, que indica que um determinado corpo de conhecimento se modifica ao receber uma nova informação, ou seja: $\mathrm{K}[\mathrm{S}]+\Delta \mathrm{I}=\mathrm{K}[\mathrm{S}+\Delta \mathrm{S}]$, onde $\mathrm{K}[\mathrm{S}]$ é o 
corpo de conhecimento original de um indivíduo, $\Delta$ I é a informação recebida e $\mathrm{K}[\mathrm{S}+\Delta \mathrm{S}]$ o novo corpo de conhecimento, modificado pela informação incorporada.

Note-se que a variação no corpo de conhecimento do indivíduo é provocada pela nova informação, mas não corresponde exatamente a ela, uma vez que essa variação depende da interpretação daquela informação e sua combinação com o conhecimento anteriormente existente. Uma mesma informação, portanto, produzirá diferentes variações de conhecimento em indivíduos distintos.

Brookes (1980) também entende que informação e conhecimento têm a mesma natureza, tanto que poderiam ser "somados" na equação. Desta forma, descreve o conhecimento como uma rede e a informação como uma parte dessa rede, aproximando-se da proposta de Farradane (1980).

\subsection{Visões da gestão do conhecimento}

A gestão do conhecimento não se originou na Academia, tendo sido, como aponta Wiig (1997), inicialmente conduzida basicamente por organizações empresariais e consultorias, com reduzida participação da pesquisa científica e largamente baseada em percepções e experiências pessoais.

Possivelmente por isso, na primeira geração da gestão do conhecimento, como definem McElroy (2003) e Dalkir (2017), o foco de atuação estava em explicitar e registrar o conhecimento existente, em geral por meio de sistemas computacionais, e fazê-lo chegar a quem dele necessitasse na realização de seu trabalho.

Nesse momento, a gestão do conhecimento recebeu grande influência do trabalho de Nonaka e Takeuchi (1995) e trazia a ideia de que as organizações poderiam extrair o conhecimento dos indivíduos e registrá-los em documentos e bases de dados para que pudessem ser compartilhados.

Nonaka e Takeuchi (1995) propuseram a ideia de um ciclo de conversão do conhecimento, de tácito, aquele que existe na mente do indivíduo, a explícito, o que está expresso em algum código, e vice-versa. Esse ciclo é constituído de quatro etapas: (a) externalização do conhecimento tácito para explícito; (b) 
combinação de conhecimentos explícitos; (c) internalização de conhecimento explícito; (d) socialização, quando indivíduos compartilham conhecimento tácito sem explicitá-lo.

Essa ideia de conhecimento tácito e explícito inspira-se nas propostas de Polanyi (1966), embora com uma intepretação própria do conceito, questionada por outros autores, como Alee (2003), Wallace (2007) e Grant (2007) que a consideram uma simplificação. Apesar dessa crítica, entretanto, reconhecem sua utilidade para a discussão do compartilhamento de conhecimento nas organizações.

Além do ciclo de conversão tácito-explícito, Nonaka e Takeuchi (1995) reconhecem que o conhecimento é criado apenas por indivíduos, sendo a criação de conhecimento numa organização um processo que amplifica o que foi criado pelos indivíduos por meio de uma rede de comunidades de interação que se expandem dos grupos para a organização e além de suas fronteiras.

Dalkir (2017) relata que no início dos anos 2000 houve um chamamento à academia para tornar a gestão do conhecimento objeto de pesquisas e elaboração teórica, cobrindo uma lacuna que Wiig (1997) considerava indispensável para que a disciplina pudesse oferecer uma resposta efetiva para a evolução sustentável das organizações.

Nessa época, ganhava espaço a segunda geração quando, explica McElroy (2003), a preocupação se voltou mais para a criação do conhecimento, entendendo esse fenômeno como eminentemente social, que ocorre nas interações entre os indivíduos. Dalkir (2017) destaca a percepção das dimensões cultural e humana do conhecimento que marcou essa geração, substituindo a ênfase em explicitar e registrar pela busca da inovação a partir dos indivíduos em grupos.

O amadurecimento da gestão do conhecimento e sua consolidação como disciplina levaram a avanços também na padronização e em sua inclusão nas melhores práticas de gestão, traduzida na publicação da Norma ISO 9001 (ISO, 2015), voltada à qualidade dos processos, que traz uma seção importante sobre gestão do conhecimento. A partir dessa evolução do entendimento da importância do tema, foi publicada uma norma especifica sobre gestão do 
conhecimento, a ISO 30401 (ISO, 2018) que descreve os requisitos de um sistema de gestão do conhecimento.

Essa norma consolida a ideia de que o conhecimento em si não pode ser gerenciado, uma vez que existe apenas na mente das pessoas. Propõe, então, um sistema de gestão do conhecimento, constituído de uma série de elementos que, por meio de uma abordagem sistemática, planejada e estruturada, viabilizam a criação de valor para a organização pelo uso efetivo do conhecimento, considerando que não há apenas uma abordagem de gestão do conhecimento. Cada organização deve definir a sua, conforme seu contexto e objetivos.

O sistema de gestão do conhecimento, ainda segundo a norma ISO 30401 (ISO, 2018) deve atuar sobre o conjunto de habilitadores relacionados no Quadro 1, integrando-os e articulando-os para que seja efetivo.

Quadro 1 - Habilitadores do sistema de gestão do conhecimento.

\begin{tabular}{|l|l|}
\hline \multicolumn{1}{|c|}{ Habilitador } & \multicolumn{1}{c|}{ Descrição } \\
\hline Capital Humano & Papéis e responsabilidades, incluindo os stakeholders do sistema. \\
\hline Processos & $\begin{array}{l}\text { Atividades de conhecimento aplicadas aos processos de trabalho } \\
\text { contemplando, dentre outras, descoberta e detecção de } \\
\text { conhecimentos, lições aprendidas e disseminação. }\end{array}$ \\
\hline $\begin{array}{l}\text { Tecnologia e } \\
\text { Infraestrutura }\end{array}$ & $\begin{array}{l}\text { Canais digitais, espaços de trabalho físicos e virtuais e outras } \\
\text { ferramentas. }\end{array}$ \\
\hline Governança & $\begin{array}{l}\text { Estratégia, expectativas e meios de assegurar que o sistema de } \\
\text { gestão do conhecimento funciona de acordo com os objetivos }\end{array}$ \\
\hline Cultura & Atitudes e normas relativas ao compartilhamento e aprendizado. \\
\hline
\end{tabular}

Wiig (1997), ao apresentar sua visão do futuro da gestão do conhecimento, sugeria que esta, assim como outras disciplinas de gestão que se mostram indispensáveis para as organizações, deve desaparecer como prática explícita, sendo assimilada totalmente e integrada aos procedimentos gerais de gestão. Prusak (2001), da mesma forma, estima que no futuro a gestão do conhecimento se tornaria uma parte tão natural de como as pessoas organizam e executam seu trabalho que se tornaria virtualmente invisível como disciplina. Nesse estágio, haveria uma gestão pelo conhecimento, abrangendo todos os aspectos da organização que teria o conhecimento como o ativo central e mais valioso. 


\subsection{Processos de gestão do conhecimento}

Dalkir (2017), consolidando as visões de diversos autores, descreve o processo de gestão do conhecimento da seguinte forma: o conhecimento se origina em processos de captura, de criação ou da contribuição de conhecimentos já existentes. Esse novo conhecimento proposto passa por um filtro que irá avaliar sua pertinência para a organização. Uma vez aceito, o conhecimento será codificado e refinado antes que possa ser compartilhado na organização. Quando compartilhado, será acessado por quem dele necessita, que, por sua vez, aprenderá a partir dele e o aplicará nas suas atividades de trabalho. A partir da aplicação, o conhecimento compartilhado será avaliado quanto a sua utilidade, podendo ser descartado ou armazenado para reutilização.

A própria Dalkir (2017), entretanto, reconhece que o que se pode registrar e digitalizar é a informação, não o conhecimento, que existe apenas nas mentes dos indivíduos.

A forma como se compreende o processo de gestão do conhecimento dependerá largamente da forma como se compreende o fenômeno do conhecimento num grupo social, como uma organização empresarial, governamental ou do terceiro setor. É sobre esse processo social que atuará a gestão do conhecimento e a forma como será percebido influirá em um eventual modelo de maturidade.

Choo (2002) trata geração de conhecimento como um ciclo no qual a organização processa informação para atribuir um significado a seu ambiente, para criar novo conhecimento e para tomar decisões. $\mathrm{O}$ autor apresenta o ciclo do conhecimento na organização como se repetindo continuamente e, além disso, com um fluxo constante de informações de e para o ambiente, conforme ilustra a Figura 2. 
Figura 2 - O ciclo de conhecimento na organização.

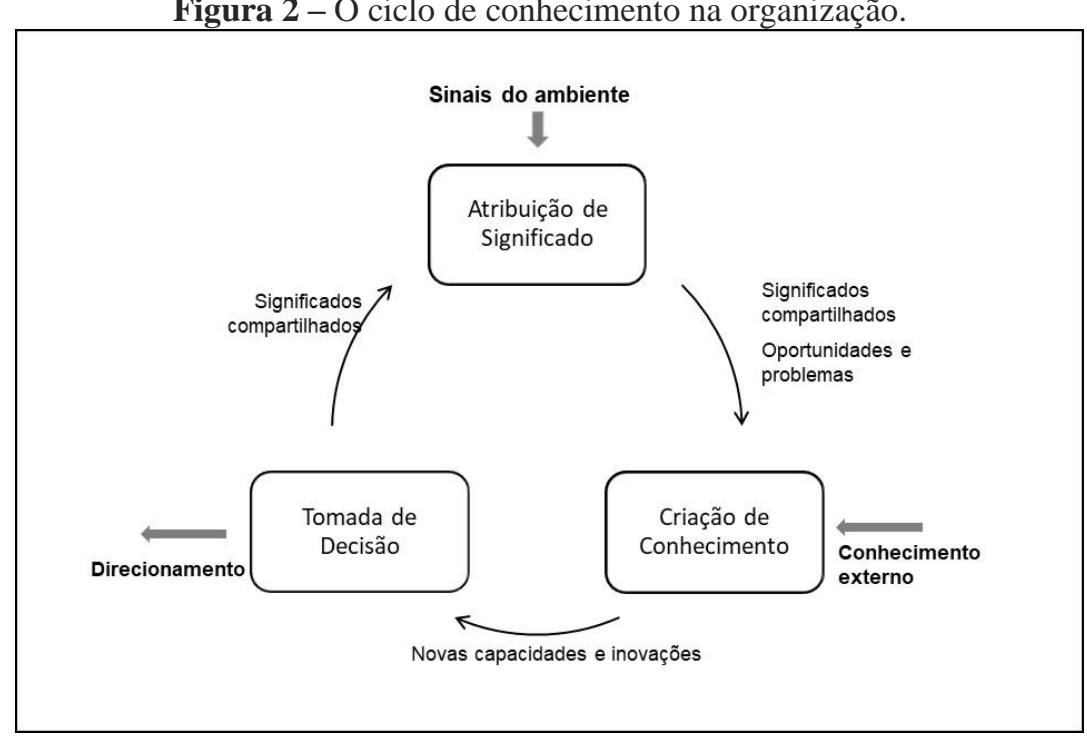

Fonte: Adaptado de Choo (2002).

Segundo Choo (2002), a organização atribui significado aos sinais que recebe do ambiente, organizando informações e interpretando-as a partir do conhecimento existente, o que pode apontar lacunas que devem ser preenchidas.

O processo de criação do conhecimento buscará preencher as lacunas percebidas, tendo como fontes o conhecimento interno já existente ou conhecimento adquirido do exterior. As capacidades criadas a partir daí irão alimentar o processo de decisão, determinando novos direcionamentos e compondo a base de conhecimento da organização.

McElroy (2003), em linha semelhante, descreve o ciclo de vida do conhecimento com dois lados complementares. Num deles estão as atividades mais ligadas a distribuir o conhecimento existente, registrando-o e fazendo-o chegar a quem dele necessita, no que o autor chama integração do conhecimento. No outro lado, estão os aspectos relacionados à produção do conhecimento em resposta a eventuais lacunas percebidas na base de conhecimento da organização, incluindo-se aí aprendizado, aquisição de conhecimento externo e formulação de novas propostas de conhecimento.

Os dois lados se complementam e se suportam, constituindo um ciclo contínuo de produção, distribuição e uso de conhecimento, conforme descrito na Figura 3. 
Figura 3 - O ciclo de vida do conhecimento.

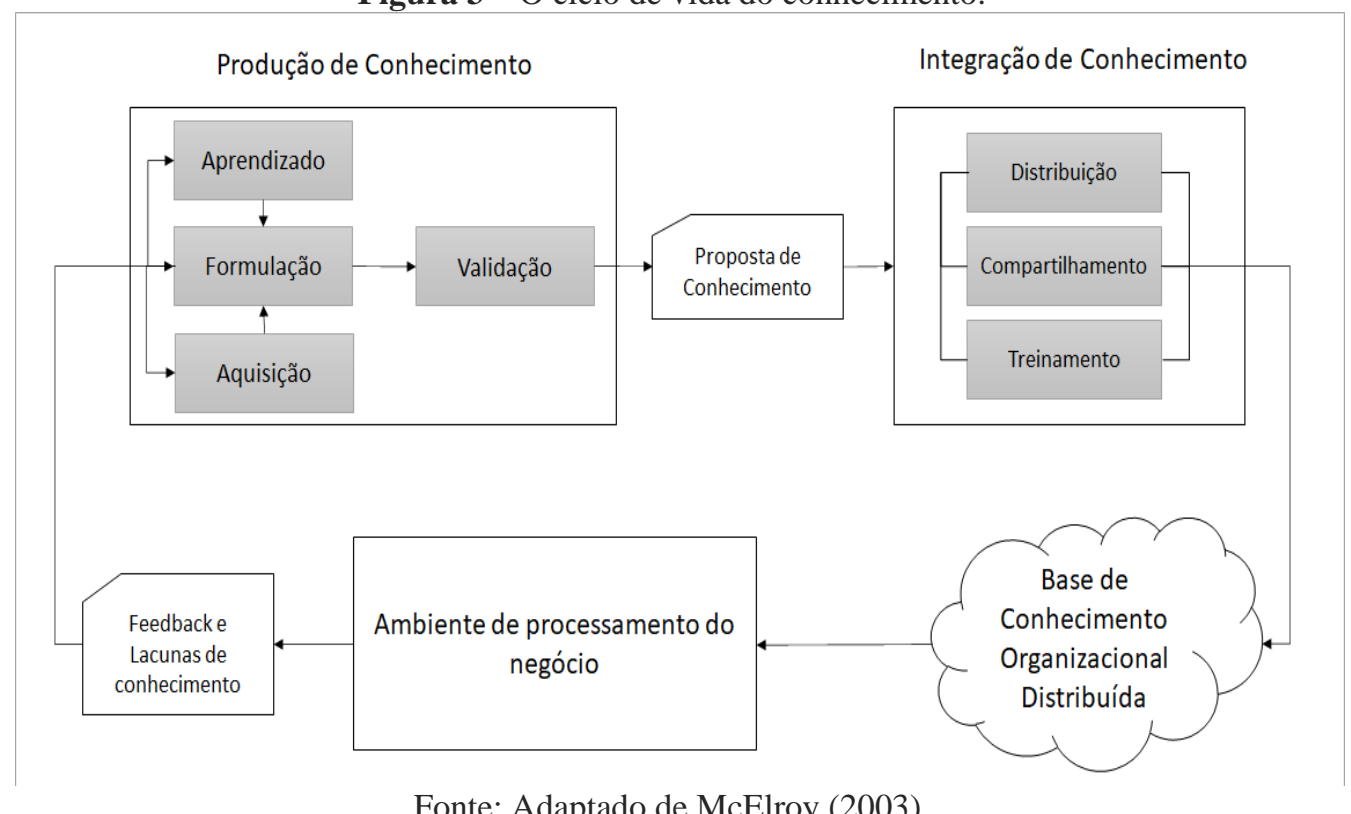

Fonte: Adaptado de McElroy (2003).

McElroy (2003) também distingue dois modos de funcionamento da organização. Um está associado ao processo básico de negócio, outro ao processo de criação e distribuição do conhecimento. O que os conecta é a base de conhecimento organizacional distribuída. O processo do conhecimento será iniciado quando for identificada uma lacuna na base de conhecimento da organização durante a execução do seu processo de negócio.

A base de conhecimento organizacional distribuída seria formada por um conjunto de repositórios de conhecimento - que serão, essencialmente, agentes, ou seja, pessoas e grupos - apoiados por artefatos na forma de documentos, livros ou sistemas de computador que armazenam informação. As pessoas dão significado a essas informações e criam valor ao usá-las integrando-as ao seu conhecimento.

Numa organização existem várias instâncias do ciclo do conhecimento aninhadas, desde aquele que ocorre num indivíduo isoladamente, às interações dentro de um grupo e até alcançar a organização como um todo, reproduzindo, em cada nível, um ciclo semelhante.

Esses diferentes níveis do ciclo de conhecimento, também presentes na proposta de Nonaka e Takeuchi (1995), devem, necessariamente, ser levadas em consideração nas ações de gestão do conhecimento. Dalkir (2017), por sua vez, destaca a ideia de que o conhecimento não reside apenas nas mentes dos 
indivíduos, mas também nas conexões entre esses indivíduos, construindo, de certa forma, uma mente coletiva.

Pode-se, então, ampliar a ideia do conhecimento como uma rede de informações proposta por Brookes (1980) e Farradane (1980) para além da mente individual. Essa estrutura poderia alcançar a mente coletiva de um grupo de indivíduos e, por consequência, da organização e, até mesmo, estender-se além de suas fronteiras.

A gestão do conhecimento teria em vista essa mente coletiva, composta pelos indivíduos, repositórios de conhecimento que a compõe, e é constantemente modificada por um ciclo de criação e revisão de conhecimento. Gerir o conhecimento seria atuar nos habilitadores desse ciclo, assegurando sua disponibilidade e funcionamento adequado.

\section{Modelos de maturidade em gestão do conhecimento}

Kraemer et al. (2017) realizaram uma revisão sistemática da literatura sobre maturidade de gestão do conhecimento identificando trabalhos em cinco categorias: proposição de novos modelos, relacionamento entre maturidade e outras variáveis, análise de fatores nas mudanças de nível, aplicações e avaliação de modelos existentes. Deste levantamento, concluíram que muitos dos modelos ainda adotam uma visão rígida e vinculada à tecnologia, provavelmente em função da frequente inspiração no CMM (PAULK et al., 1993).

Damian, Silva e Valentim (2017) realizaram um estudo comparativo entre modelos de maturidade em gestão do conhecimento identificados na literatura a fim de verificar convergências e divergências quanto aos eixos principais (níveis e dimensões) e perceber em que medida um modelo de maturidade pode apoiar o esforço de implantação ou evolução da gestão do conhecimento numa organização.

A partir dessa análise, as autoras apontam que a grande maioria dos modelos estão organizados em níveis que vão de um estado em que a gestão do conhecimento não é compreendida ou organizada até um onde há consciência e 
controle e os processos de conhecimento estão integrados à gestão da organização.

Essa ideia de estágios auxilia as organizações a compreender sua situação presente e identificar um plano de ação para evolução e, ainda que haja variação entre os elementos avaliados, é comum a presença de aspectos relacionados a pessoas, processos e tecnologia. Entretanto, fatores críticos de sucesso, tais como liderança, cultura organizacional e apoio da alta administração, deveriam ser tratados nesses modelos, pois estão na origem de muitas das falhas em projetos de gestão do conhecimento.

Damian, Silva e Valentim (2017) destacam como muito importante que a gestão do conhecimento deva ser compreendida como um modelo de gestão da organização, integrando todos os processos e perspectivas.

Pee e Kankanhali (2009) também realizaram uma revisão de uma série de modelos de maturidade em gestão do conhecimento, sendo parte deles baseados na estrutura do CMM (PAULK et al., 1993) e parte com arquiteturas próprias. A partir dessa análise, os autores propuseram o que seria um Modelo Geral de Maturidade de Gestão do Conhecimento ou G-KMMM. Os níveis de maturidade do G-KMMM vão de um estágio onde a organização não tem intenção de gerir o conhecimento, evolui pela conscientização, a definição de processos básicos, sua padronização, gerenciamento e mensuração e culmina com a gestão do conhecimento profundamente integrada na organização, como um componente automático de todo processo organizacional, e em constante aperfeiçoamento.

Kulkarni e St Louis (2003) desenvolveram um modelo de maturidade também inspirado no CMM, onde os níveis propostos pelos autores têm como eixo principal o compartilhamento de conhecimento. Os níveis são 1 (possível), quando há uma disposição de compartilhar, mas depende de iniciativa dos indivíduos; 2 (encorajado), quando a organização reconhece o valor do conhecimento e estimula o compartilhamento; 3 (praticado), quando o compartilhamento é efetivo e as atividades relativas fazem parte das rotinas de trabalho; 4 (gerenciado), quando o compartilhamento é facilitado por processos e ferramentas, e 5 (constantemente aperfeiçoado), quando mecanismos e 
ferramentas para alavancar o conhecimento na organização são largamente aceitos e utilizados. O modelo sugere um conjunto de Áreas de Gestão do Conhecimento (KMA), mas ressalta que essas áreas não são universais ou definitivas, podendo ser ajustadas conforme a organização. As áreas originalmente consideradas reforçam o foco no compartilhamento do conhecimento e são: lições aprendidas, expertise, dados e conhecimento estruturado.

Oliveira et al. (2011) e Oliveira e Pedron (2014) também propuseram um modelo de maturidade em gestão do conhecimento a partir da avaliação de outros modelos da literatura. Neste caso, foram avaliados oito modelos com foco especial nos benefícios estratégicos que pudessem ser alcançados com seu uso. $\mathrm{O}$ modelo resultante dessa análise, denominado KM3, é composto de cinco níveis, sendo 0 (falta de consciência), quando a organização não percebe o valor da gestão do conhecimento; 1 (planejamento), quando começa a haver o planejamento de algumas iniciativas; 2 (iniciação), quando as iniciativas são postas em prática; 3 (avaliação), quando iniciativas melhoradas são avaliadas com uso de métricas e 4 (integração), quando as iniciativas de gestão do conhecimento são desenvolvidas internas e externamente, com o objetivo de desenvolver o conhecimento em rede. As dimensões consideradas são: (a) contexto interno, que inclui suporte institucional e tecnologia; (b) contexto externo, envolvendo clientes, fornecedores e parceiros; (c) processos, que considera criação, armazenamento e compartilhamento; (d) conteúdo, incluindo conhecimento tácito e explícito.

Os modelos considerados nesta seção apresentam variações que podem ser entendidas como decorrentes do contexto e das finalidades em que foram desenvolvidos. Percebe-se uma influência importante do CMM, ainda que por vezes o que ocorra seja uma transposição da ideia de níveis e dos respectivos nomes apenas, alterando-se bastante o contexto e a abordagem de aplicação.

De forma geral, os modelos propõem níveis que vão de um estágio em que não há interesse ou valorização da gestão do conhecimento até uma situação de grande integração com os demais processos organizacionais. 
A principal vantagem de um modelo de maturidade, pode-se observar, seria oferecer às organizações um instrumento para avaliar sua situação corrente, identificar as questões que precisa tratar e qual poderia ser um caminho de evolução.

As dimensões mais comuns nos modelos estudados, embora com variações de ênfase, envolvem aspectos ligados a pessoas, processos e infraestrutura, sendo que, em alguns casos, essas dimensões incluem cultura, gestão, organização e tecnologia.

\section{Proposta de modelo de maturidade em gestão do conhecimento}

Conforme discutido na seção anterior, ainda que existam vários modelos de maturidade voltados à gestão do conhecimento, nenhum pode ser considerado como referência universal, única e consensual. Mesmo que existam características comuns entre eles, na maior parte das vezes, cada um reforça alguns aspectos específicos inspirados pelo contexto em que se desenvolveram.

O que se busca aqui não é esse desenho definitivo, mas sim propor um modelo que se construa em torno de dimensões e níveis que atendam a uma ampla gama de organizações, oferecendo a flexibilidade necessária para o ajuste às diferentes estratégias.

O modelo proposto, que será designado por Modelo de Maturidade em Gestão do Conhecimento (MMGC), segue o desenho de arquitetura descrito na Seção 3, ilustrado na Figura 1, composta de um conjunto de dimensões que são avaliadas, cada uma delas, segundo níveis de maturidade.

Essa arquitetura oferece, a um mesmo tempo, uma visão abrangente da maturidade da gestão do conhecimento, desdobrada em seus elementos fundamentais, enquanto mantém suficiente flexibilidade para permitir que se possa ajustá-lo às peculiaridades de cada organização.

\subsection{Dimensões do modelo de maturidade}

O MMGC adota a visão de que a organização deve definir um sistema de gestão do conhecimento, como propõe a ISO 30401 (ISO, 2018). Esse sistema atuará 
sobre um conjunto de elementos da organização que habilitam processo de conhecimento.

A partir do que foi tratado nas seções anteriores, são propostas as seguintes dimensões para o modelo de maturidade, representando os elementos habilitadores:

a) pessoas: Trata do recrutamento e seleção de profissionais, seu treinamento e capacitação para o trabalho e as formas de comunicação. Os autores que tratam a gestão do conhecimento, em especial os associados à segunda geração, destacam a importância das pessoas como um elemento fundamental. São as pessoas que criarão e, em última instância, utilizarão o conhecimento. A maioria dos modelos de maturidade inclui pessoas como um elemento relevante. Alguns reúnem nessa dimensão outras questões, como governança, cultura e gestão. A opção foi especializar os elementos, permitindo uma avaliação mais precisa;

b) cultura: Traduz a forma como as pessoas se relacionam interna e externamente, representa parte do conhecimento prévio, indica os valores da organização, os significados compartilhados, o sentido de pertencimento e os laços estabelecidos. É um elemento presente na maioria dos autores e nos modelos de maturidade. É central na segunda geração da gestão do conhecimento e um dos princípios básicos na ISO 30.401 (ISO, 2018). Damian, Silva e Valentim (2017) apontam a cultura organizacional como um dos principais fatores críticos para o sucesso da gestão do conhecimento;

c) governança: Representa os stakeholders da organização - atores que têm interesse e influência no seu desempenho - e a alta administração, cujo apoio e patrocínio são fundamentais. A governança explicita e reforça valores e princípios, aponta a missão, define as estratégias e estabelece os objetivos. Na maioria dos modelos, a governança é tratada dentro das dimensões Gestão ou Pessoas. O COBIT (ISACA, 2019), entretanto, distingue claramente as funções de governança e gestão, que não devem ser confundidas. Governança 
envolve a definição dos objetivos e sua priorização, a decisão e monitoramento da performance em geral. A Gestão está relacionada com o planejamento, execução e monitoramento de atividades a partir dos direcionamentos da Governança;

d) processos: Refere-se ao gerenciamento dos processos de conhecimento e às atividades que os compõem, ao seu planejamento, definição, execução, mensuração e monitoramento. Seu foco principal está na correta definição, no controle e na mensuração. A maioria dos autores, assim como os modelos de maturidade discutidos nas seções anteriores, destacam os processos como uma dimensão essencial. Alguns, inclusive, a partir da influência do CMM, tratam o gerenciamento desses processos como a própria gestão do conhecimento o que seria reducionista. Mas essa é, certamente, uma dimensão necessária;

e) arquitetura organizacional: Observa as formas de estabelecimento dos grupos de trabalho, equipes e unidades na organização e sua relação com o ambiente externo. Inclui a definição de papéis e responsabilidades e os espaços de decisão, assim como a arquitetura dos processos empresariais e as formas e canais de relacionamento internos e externos. Essa dimensão é tratada na maioria dos modelos como parte das dimensões de pessoas ou gerenciamento, conforme o caso. Entretanto, a forma que se organizam equipes, unidades e relações com o contexto externo tem muita influência na gestão do conhecimento. Em algum momento haverá equipes específicas para o tema, até mesmo papéis de alto nível tratando do conhecimento e a definição dos papéis e responsabilidades desses atores e sua relação com os demais grupos na organização será fundamental;

f) infraestrutura e tecnologia da informação: Contempla recursos físicos e tecnológicos que suportam os processos de trabalho, o registro e compartilhamento de informações, a comunicação entre indivíduos e grupos interna e externamente à organização. Vários modelos dentre os tratados na seção 5 apontam as Tecnologias da Informação e 
Comunicação (TIC) e a infraestrutura como elementos essenciais na avaliação de maturidade. A importância das TIC é consenso. Alguns autores chegam a criticar a excessiva ênfase nesse aspecto, principalmente nas primeiras implementações da gestão do conhecimento. Entretanto, a importância das TIC, assim como de outros elementos de infraestrutura, são fundamentais para a maturidade da gestão do conhecimento.

\subsection{Níveis do modelo de maturidade}

Na seção 4.1 discutiu-se os conceitos de conhecimento, estabelecendo qual seria utilizado na construção do modelo de maturidade, aquele proposto por Farradane (1980) e Brookes (1980): o conhecimento é uma rede formada na mente do indivíduo a partir de diversas partes. Estas partes seriam informações e a forma que se integram na estrutura mental depende do restante dessa mesma estrutura, ou seja, do conhecimento anterior.

Na seção 4.3 foi apresentada a ideia de que o conhecimento existe não apenas na mente do indivíduo, mas também nas conexões entre indivíduos e de que o ciclo do conhecimento ocorre em vários níveis dentro de um grupo social. Com isso, a ideia do conhecimento como uma estrutura mental foi estendida para além do indivíduo, numa mente coletiva que alcançaria o grupo de indivíduos e, por consequência, também a organização e além dela.

Seria, então, sobre essa estrutura que o sistema de gestão do conhecimento deveria atuar. E o faria gerenciando os vários habilitadores de seu funcionamento. É claro que a extensão dessa estrutura e sua complexidade guardam relação direta com a forma como o sistema de gestão do conhecimento deve tratar cada um dos habilitadores. Desta forma, seria esse o eixo de definição dos níveis de maturidade. No modelo proposto haveria, então, seis níveis de maturidade, conforme segue:

a) nível 0 (Indivíduo): O processamento do conhecimento se dá no nível do indivíduo. É ele que capta os sinais do ambiente ao executar uma tarefa e, quando não tem uma resposta em seu repertório, busca, por 
seus próprios meios, novo conhecimento. A organização não se preocupa com processos de conhecimento;

b) nível 1 (Grupo): O processamento do conhecimento se dá no nível de grupos locais, como uma equipe ou um conjunto de indivíduos próximos. Não há integração entre diferentes grupos e nem uniformidade nas suas formas de atuação. Percebida a falta de algum conhecimento na execução da tarefa, os membros do grupo buscarão em seus repertórios individuais e compartilhados ou em fontes externas o conhecimento necessário. A validação desse conhecimento se dá no âmbito do grupo, que o incorporará à sua base, em geral de maneira informal. A organização começa a reconhecer ações de gestão do conhecimento, mas o foco ainda é basicamente instrumental, não há ações integradas nem tratamento no planejamento estratégico;

c) nível 2 (Organização): O processo do conhecimento se dá no nível organizacional, de forma homogênea nos diversos grupos. A organização compreende o valor da gestão do conhecimento, atua no registro do conhecimento existente e em torná-lo disponível onde necessário. O compartilhamento é estimulado. A organização inclui metas relativas à gestão do conhecimento em seu planejamento e acompanha seu desempenho com métricas, em geral, relacionadas ao registro e distribuição;

d) nível 3 (Inovação): $O$ processamento do conhecimento, já estabelecido na organização, passa a ter foco na criação do conhecimento e na inovação. A identificação de necessidades, validação de novos conhecimentos e sua incorporação às bases organizacionais são conduzidas de forma institucional, com base em políticas e estruturas organizacionais especializadas, sem que isso signifique rigidez ou impessoalidade. Criação de conhecimento, inovação e pensamento crítico são estimulados. A organização considera o conhecimento um ativo valioso, busca formas de medi-lo, inclui o tema em seu planejamento estratégico e busca incorporá-lo em seus produtos e serviços como um diferencial; 
e) nível 4 (Rede): A organização vê o conhecimento como seu principal ativo e o incorpora intensamente em produtos e serviços, de forma consciente e planejada. Compartilha conhecimento em sua cadeia de valor e atua em conjunto com parceiros externos e clientes na inovação e na identificação de novos conhecimentos. A organização tem fronteiras fluidas e a colaboração é intensa;

f) nível 5 (Plenitude): Os processos de gestão do conhecimento, assim como equipes, papéis e estruturas específicas deixam de existir formalmente e passam a estar totalmente incorporados nas atividades do dia a dia em todos os níveis operacionais. A inovação e o compartilhamento de conhecimento são parte fundamental da cultura organizacional e praticadas naturalmente por todos os indivíduos. A organização conduz todos os seus processos de gestão com base no conhecimento. Passa a existir uma gestão pelo conhecimento.

\subsection{O perfil de maturidade da organização}

No desenho deste modelo de maturidade, a opção foi usar uma arquitetura onde não se define um nível único de maturidade para o sistema como um todo, mas sim um perfil, composto dos níveis de maturidade de cada uma das dimensões do sistema de gestão do conhecimento.

Figura 5 - Exemplo de representação do perfil de maturidade do sistema de gestão do conhecimento.

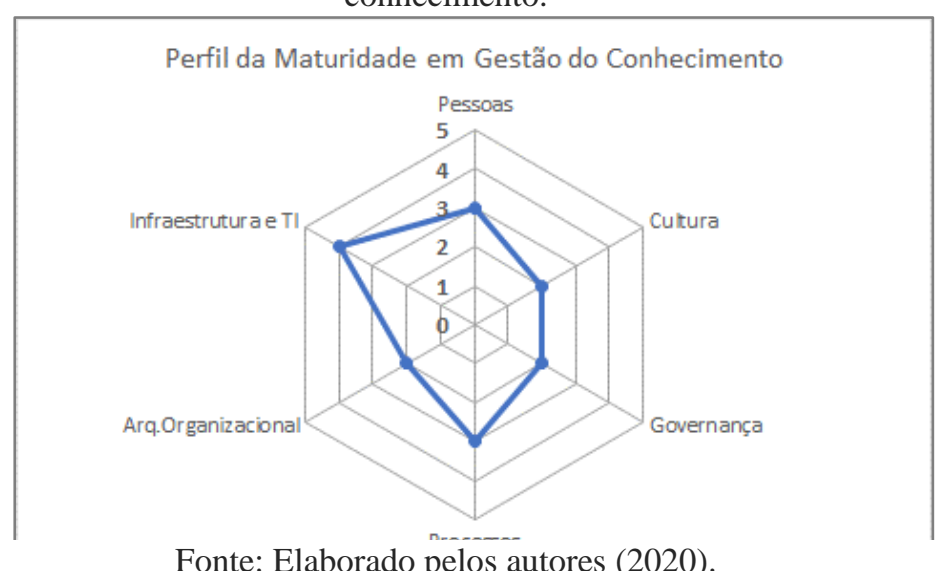

Fonte: Elaborado pelos autores (2020).

O perfil de maturidade poderá ser descrito na forma ilustrada da Figura 5, por exemplo. Outras formas de representação também podem ser utilizadas, 
cabendo a escolha ao eventual aplicador do modelo ou à organização, conforme parecer mais conveniente aos seus propósitos.

\section{Considerações finais}

O Modelo de Maturidade em Gestão do Conhecimento (MMGC) proposto buscou dar ênfase no aspecto social do conhecimento, considerando que os conceitos associados são relativos ao ambiente de trabalho, formando um conjunto de elementos organizacionais que habilitam a geração e compartilhamento do conhecimento.

A pesquisa examinou, além de outros modelos de maturidade já publicados na literatura, a própria evolução da disciplina de gestão do conhecimento, sobretudo no que diz respeito aos resultados para o processo de inovação.

As dimensões do modelo correspondem a elementos da organização que são habilitadores dos processos de conhecimento. A gestão do conhecimento atua sobre esses elementos de forma a criar um contexto favorável a que os indivíduos, interagindo em grupos de várias configurações, criem e partilhem o conhecimento. Essas dimensões são: pessoas, cultura, governança, processos, arquitetura organizacional e infraestrutura e tecnologia. Quanto melhor gerenciados forem esses elementos, melhores as condições para que o conhecimento seja criado e devidamente trabalhado.

Essa evolução da gestão, no MMGC, avança por níveis de complexidade das interações sociais, começando do indivíduo (nível 0, onde não há efetiva gestão do conhecimento), passando pelos grupos (nível 1) até a organização como um todo (nível 2). Deste nível, evolui para que a organização seja inovadora (nível 3) e que essa inovação se estenda pela rede de organizações (nível 4). A gestão do conhecimento alcança a plenitude (nível 5) quando se torna a própria natureza da organização.

O modelo, na forma como aqui apresentado, pode oferecer uma estratégia para o planejamento da implantação ou evolução da gestão do conhecimento nas organizações. As dimensões propostas e a estruturação do 
modelo em uma arquitetura que permite avaliações de cada uma dessas dimensões de forma independente e não em estágios rigidamente pré-definidos, oferece a possibilidade de adequação a diferentes contextos e estratégias, abordagem mais adequada à complexidade inerente à gestão do conhecimento.

Os resultados apresentados neste artigo se limitaram a propor o modelo de maturidade, não contemplando a elaboração de um instrumento de avaliação e sua aplicação a um caso real. Esses são próximos passos de pesquisa.

\section{Referências}

ALEE, Verna. The future of Knowledge: Increasing Prosperity through Value Networks. New York: Elsevier Science, 2003.

BROOKES, Bertrand. The Foundations of Information Science. Part I: Philosophical Aspects. Journal of Information Science, London, v. 2, n. 2, p. 125-133, 1980.

CHOO, Chun Wei. Sensemaking, Knowledge Creation and Decision Making. In: CHOO, C.W.; BONTIS, N. (org.). The Strategic Management of Intellectual Capital and Organizational Knowledge. New York: Oxford University Press, 2002.

CMMI Product Team. Capability Maturity Model Integration, Version 1.1 CMMI for Systems Engineering, Software Engineering and Integrated Product and Process Development. Pittsburg: Carnegie Mellon University/SEI, 2001.

DALKIR, Kimiz. Knowledge Management in Theory and Practice. Cambridge: MIT Press, 2017.

DAMIAN, Ieda; SILVA, Elaine; VALENTIM, Marta Lígia. Contribuição dos Modelos de Maturidade para a Gestão do Conhecimento em Contextos Organizacionais. In: VIII Encontro Iberico EDCIC. Coimbra: Universidade de Coimbra, 2017.

DROUIN, Jean. The Spice Project. In: El EMAN, K.; MAGHAVJI, N. (org.). Elements of Software Assessment and Improvement. Los Alamitos: Computer Society Press, 1999.

ESCRIVÃO, Giovana; SILVA, Sérgio Luís da. Knowledge management maturity models: identification of gaps and improvement proposal.

Gestão\&Produção, São Carlos, v. 26, n. 3, 2019. 
FARRADANE, Jason. Knowledge, Information and Information Science. Journal of Information Science, London, v.2, n.1, p 75-80, 1980.

GRANT, Keneth. Tacit Knowledge Revisited: We can still learn from Polanyi. Electronic Journal of Knowledge Management, Wilton, v.5, n.2, p.173-180, 2007.

ISACA. COBIT 2019 Framework - Introduction and Methodology. Schaumburg, EUA: ISACA, 2019.

ISO. ISO 30.401 - Knowledge Management Systems - Requirements. Geneve: ISO, 2018.

ISO. ISO 9001 - Quality Management Systems: Requirements. Geneve: ISO, 2015.

KRAEMER, Rodrigo et al. Maturidade de Gestão do Conhecimento: uma revisão sistemática da literatura para apoiar o desenvolvimento de novos modelos de avaliação. Perspectivas em Gestão \& Conhecimento, João Pessoa, v. 7, Número Especial, p. 66-79, 2017.

KULKARNI, Uday.; ST LOUIS, Robert. Organizational Self-Assessment of Knowledge Management Maturity. Americas Conference on Information Systems (AMCIS), 2003, Tampa. Anais [...], v.1. n.1, p. 2542-2551. Tampa: AMCIS, 2003.

LASRADO, Lester Allan; VATRAPU, Ravi; ANDERSEN, Kim Normann. Maturity Models Development in IS Research: a literature review. In: INFORMATION SYSTEMS RESEARCH SEMINAR IN SCANDINAVIA (IRIS 2015), 38, 2015, Oulu, Finland. Anais [...]. Oulu, Finland: Scandinavian Chapter of the Association for Information Systems (AIS), 2015.

McELROY, Mark. The New Knowledge Management: Complexity, Learning and Sustainable Innovation. Burlington, MA: Butterworth-Heinemann, 2003.

NONAKA, Ikujiro; TAKEUCHI, Hirotaka. The Knowledge-Creating

Company. New York: Oxford University Press, 1995.

OLIVEIRA, Mirian et al. Proposta de um Modelo de Maturidade para Gestão do Conhecimento: KM3. Revista Portuguesa e Brasileira de Gestão, Rio de Janeiro, v.10, n.4, p.11-25, 2011. 
OLIVEIRA, Mirian; PEDRÓN, Cristiane. Maturity Model for Knowledge Management and Strategic Benefits. Proceedings of the European Conference on Knowledge Management, 2014, Santarém-Portugal. Proceedings [...]. Santarém: European Conference on Knowledge Management, 2014.

PAULK, Mark et al. Capability Maturity Model for Software, Version 1.1 Pittsburg: Software Engineering Institute, Carnegie-Mellon University,1993.

PEE, L.G.; KANKANHALI, A. A Model of Organizational Knowledge Management Maturity based on People, Process and Technology. Journal of Information \& Knowledge Management, Singapur, v. 8, n. 2, p. 1-21, 2009.

POLANYI, Michael. The Tacit Dimension. London: University of Chicago Press, 1966.

PRUSAK, Laurence. Where dis Knowledge Management Came From? IBM Systems Journal, Riverton, v.40, n. 4, p. 1002-1007, 2001.

WALLACE, Danny. Knowledge Management: Historical and CrossDisciplinary Themes. Londres: Libraries Unlimited, 2007.

WIIG, Karl. Knowledge Management: Where it Came from and Where Will It Go? Expert Systems with Applications, Arlington, v. 13, n.1, p. 1-14, 1997.

\title{
Knowledge magement maturity model: a diachronic perspective
}

\begin{abstract}
This paper proposes a knowledge management maturity model based on literature review of existing models and having in mind the fundamentals of knowledge management and its evolution. The methodology used was an exploratory qualitative research, with literature review based on the ranking generated by the free access applicative Public or Perish using a variety of data sources (such as Google Scholar and Microsoft Academic Search). The resulting model complies with ISO 30401 (Knowledge Management Systems), with a set of 6 dimensions: People, Culture, Governance, Processes, Organizational Architecture and Infrastructure and Technology, representing the main enablers of knowledge, and six levels: 0 - Individual, 1 - Group, 2 - Organization, 3 Innovation, 4 - Network, 5 - Fullness, representing the path of knowledge management evolution. The proposed model is based on a concept of knowledge as a social and mental phenomenon that cannot be managed directly. The conclusion, therefore, is that the maturity of knowledge management in an organization can be represented as individual maturity levels for a set of knowledge enablers that constitutes the profile of the knowledge management system and shows how effective it can be.
\end{abstract}


Keywords: Maturity model. Knowledge management. Knowledge management maturity model. ISO 30401.

Recebido: $19 / 07 / 2020$

Aceito: 02/12/2020

\section{Declaração de Autoria}

Concepção e elaboração do estudo: A. Itaborahy, R. Machado, L. Alvares

Coleta de dados: A. Itaborahy, R. Machado, L. Alvares

Análise e discussão de dados: A. Itaborahy, R. Machado, L. Alvares

Redação e revisão do manuscrito: L. Alvares

\section{Como Citar}

ITABORAHY, Anderson Luis Cambraia; MACHADO, Renato Plácido

Mathias; ALVARES, Lillian Maria Araújo de Resende. Modelo de maturidade em Gestão do Conhecimento: uma visão diacrônica. Em Questão, Porto Alegre, v. 27, n. 3, p. 350-374, 2021. Doi: http://dx.doi.org/10.19132/1808-

5245273.350-374

${ }^{1}$ Em 1991 foi publicada a primeira versão do Capability Maturity Model for Software - o CMM (Paulk, 1991; Weber, 1991). Em 1993 foi publicada a versão 1.1 do SW-CMM (Paulk et al., 1993), que consolidou o modelo.

${ }^{2}$ O Projeto SPICE resultou na Norma ISO/IEC 15504 que, posteriormente, passou a fazer parte da família de normas ISO/IEC 33000, especialmente a ISO/IEC 33004 - Modelos de Avaliação e Maturidade de Processos (no original em inglês, Process Assesment and Maturity Models). 